\title{
Article \\ Do COVID-19-Related Stress, Being Overweight, and Body Dissatisfaction Contribute to More Disordered Eating in Polish Women?-A Cluster Analysis Approach
}

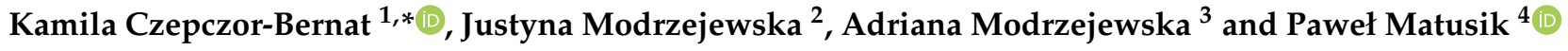 \\ 1 Institute of Psychology, University of Wrocław, 50-527 Wrocław, Poland \\ 2 Institute of Pedagogy, University of Bielsko-Biala, 43-309 Bielsko-Biala, Poland; jmodrzejewska@ath.bielsko.pl \\ 3 Department of Psychology, School of Health Sciences in Katowice, Medical University of Silesia in Katowice, \\ 40-055 Katowice, Poland; adriana.modrzejewska@sum.edu.pl \\ 4 Department of Pediatrics, Pediatric Obesity and Metabolic Bone Diseases, Faculty of Medical Sciences in \\ Katowice, Medical University of Silesia, 40-055 Katowice, Poland; pmatusik73@gmail.com \\ * Correspondence: kamila.czepczor-bernat@uwr.edu.pl
}

\section{check for}

updates

Citation: Czepczor-Bernat, K.; Modrzejewska, J.; Modrzejewska, A.; Matusik, P. Do COVID-19-Related Stress, Being Overweight, and Body Dissatisfaction Contribute to More Disordered Eating in Polish Women?-A Cluster Analysis Approach. Int. J. Environ. Res. Public Health 2021, 18, 13100. https:// doi.org/10.3390/ijerph182413100

Academic Editor: Lorys Castelli

Received: 27 October 2021

Accepted: 11 December 2021

Published: 12 December 2021

Publisher's Note: MDPI stays neutral with regard to jurisdictional claims in published maps and institutional affiliations.

Copyright: (c) 2021 by the authors. Licensee MDPI, Basel, Switzerland. This article is an open access article distributed under the terms and conditions of the Creative Commons Attribution (CC BY) license (https:// creativecommons.org/licenses/by/ $4.0 /)$.

\begin{abstract}
We hypothesized that women who are overweight, experiencing COVID-19-related stress, and with high body dissatisfaction would have significantly greater disordered eating than those of healthy weight, without stress, and with low body dissatisfaction. Participants ( $N=1354$ women; $M_{\text {age }}=31.89$ years, $S D=11.14$ ) filled in the Contour Drawing Rating Scale, the Emotional Overeating Questionnaire, the Eating Motivation Survey, the Mindful Eating Questionnaire, and a COVID-19related stress measure and sociodemographic survey. The cluster analysis technique revealed four distinct clusters: (a) Cluster $1(N=314)$ : healthy body weight, no COVID-related stress, and low body dissatisfaction $(M=1.19)$; (b) Cluster $2(N=131)$ : overweight, no COVID-related stress, and high body dissatisfaction $(M=2.41)$; (c) Cluster 3 ( $N=597)$ : healthy body weight, COVID-related stress, and low body dissatisfaction $(M=1.27)$; (d) Cluster $4(N=312)$ : overweight, COVID-related stress, and high body dissatisfaction $(M=2.84)$. Generally, our outcomes partially support our hypothesis, as higher levels of some types of disordered eating were observed in women who were overweight with COVID-related stress and high body dissatisfaction (Cluster 4) as compared with women with healthy body weight, no COVID-related stress, and with low levels of body dissatisfaction (Cluster 1). Our results indicate that both body weight status, as well as COVID-19-related stress and body dissatisfaction, may contribute to the intensity of disordered eating. During future epidemic-related quarantines, this may be an argument in favor of organizing support regarding emotional functioning, body image, and eating behaviors, particularly for the most vulnerable groups-including overweight and obese women.
\end{abstract}

Keywords: COVID-19-related stress; overweight; body dissatisfaction; disordered eating; women

\section{Introduction}

There have been a lot of data published recently on the impact of the coronavirus pandemic on health [1-3]. The situation has given rise to concerns for one's own health [4,5], and many reports show how COVID-19 and restrictions related to it can affect both psyche and soma [2,6-11]. Within this context, research findings have also been published on, inter alia: (a) changes in eating behavior [12-14]; (b) the relationships between COVID-19-related stress, disordered eating (e.g., emotional overeating) [15-17], symptoms of eating disorders, and negative body image [18-22]; (c) the functioning of people who are overweight and have possible changes in body weight $[13,23]$.

The results so far indicate that for many people, COVID-19 was (or still is) a strong source of stress [4,22,24], and its high levels can lead to unhealthy eating behaviors $[16,17,25,26]$. These changes in eating were (and may still be) related to the fact that people use food 
as a way of regulating emotions, especially in a situation where other ways of coping with anxiety, stress, and other negative emotional states have been significantly limited by restrictions related to COVID-19 (including direct contact with friends, going to the cinema and other entertainment venues, etc.) $[15,16,24,25,27,28]$. In addition, the source of negative emotions may also be COVID-related restrictions, which, at some stage of the pandemic, prevented us from practicing physical activity outdoors, in the gym, and in other places of recreation $[8,13]$. The COVID-19 situation may therefore be responsible for the weight-loss and maintenance strategies that have characterized the main changes in eating behavior. These may have led to the appearance or intensification of a feeling of lack of weight control and exacerbated perceived stress, and, as a result, led people to try to cope with these emotions in a maladaptive way (e.g., through emotional overeating) $[13,15,16,20,25,28-31]$. Moreover, previous research (conducted before COVID-19) indicated that the group of the greatest risk for the development of disturbed eating behaviors could be the group of people who are overweight, who are at the same time strongly dissatisfied with their body [32,33]. It is therefore worth asking whether and how, at the same time, these factors-COVID-19-related stress, being overweight, and body dissatisfaction — can have contributed to more disordered eating during the COVID-19 pandemic?

Referring to the category of disordered eating, it should be mentioned that this is a very broad category including, among others, emotional (over)eating and a low level of mindful eating. Emotional (over)eating can be defined as the tendency to regulate emotional states by eating (too much) food $[15,34,35]$. In turn, a low level of mindful eating is associated with (a) a high level of the diet mentality (a rigid tendency to make food choices without taking account of fullness or hunger, as well as daily life circumstances and individual preferences because the priority is body weight management); (b) a low level of the non-judgmental process of paying attention to the eating experience by listening to and having an awareness of physical hunger and satiety cues, (c) a low level of eating by engaging all of the senses and only until we are full [36]. Low levels of mindful eating and high levels of emotional eating will significantly increase the risk of weight gain $[28,37]$, which may result in an intensification of body dissatisfaction [33].

When writing about eating behaviors, it should also be mentioned that we can evaluate them by examining the motivation underlying particular food choices [38]. Referring to the situation related to COVID-19 and to the above findings, it would be worth looking at such motives of eating such as health, weight control, and affecting regulation $[4,5,15,17,25,28]$.

To sum up, although knowledge about COVID-19-related stress, body weight, and eating behaviors/disorders has increased in diverse populations [12,13,22,25], knowledge and research on the importance of body dissatisfaction to disordered eating during COVID19 remains limited. Given the likelihood that during COVID-19, in the UK, women have reported (compared to men) a stronger worsening in unhealthy eating and negative body image [39], and, taking into account previous findings (prior to COVID-19) that indicate a particularly high level of body dissatisfaction among women who are overweight [33], greater knowledge and further research is vital for a fuller understanding of this issue in women (also in the Polish sample). Therefore, our study aimed to (1) classify different conditions associated with weight status, COVID-19-related stress, and body dissatisfaction; and (2) analyze and compare disordered eating in women with different weight status, COVID-19-related stress, and body dissatisfaction. We hypothesized that women who were overweight, experiencing COVID-19-related stress, and with high body dissatisfaction, would have significantly greater disordered eating than those of healthy weight, without stress, and with low body dissatisfaction.

\section{Materials and Methods}

\subsection{Participants and Procedure}

Our cross-sectional study was approved by the University Ethics Committee (no. $2021 / 2 / 2 \mathrm{E} / 2$ ) and conducted in accordance with the international standards of research ethics (Helsinki Declaration, 2001). From January to March 2021, Polish women were 
recruited via an online advertisement (e.g., on social media networks) and flyers (posted at workplace locations, universities, etc.). After contacting the researchers, all women were made aware that participation in this study was anonymous and voluntary. Next, they were asked to read informed consent to participate in the study. After becoming acquainted with all the information, if they expressed their willingness to participate in the study, they signed this informed consent online. Next, women completed an online survey (populated on Google Forms), which was accessed via a link sent to participants. Participants were not remunerated.

One thousand five hundred and ninety-four people volunteered for the study. Two hundred and forty participants had significant missing data gaps or were outliers (due to the aim of this analysis-assessment in the group of women who were healthy or overweight-men and all those who were not overweight were removed from the database). Finally, our sample included 1354 Polish women who ranged in age from 18 to 72 years $(M=31.89, S D=11.14)$.

\subsection{Measures}

\subsubsection{The Contour Drawing Rating Scale (CDRS)}

To assess body dissatisfaction, participants completed the Contour Drawing Rating Scale [40]. The CDRS consists of nine consecutively numbered female silhouettes. Participants were asked (a) "Which silhouette reflects what you look like now?" ("real silhouette"); (b) "Which silhouette reflects what you would like to look like?" ("ideal silhouette"). The level of body dissatisfaction was assessed by subtracting the number of the silhouette indicated as "real" from the number of the silhouette indicated as "ideal", and the higher the discrepancy between them, the greater the body dissatisfaction.

\subsubsection{The Emotional Overeating Questionnaire (EOQ)}

To assess emotional overeating, participants completed the Emotional Overeating Questionnaire [41]. The nine-item EOQ measures how often people have eaten excessive amounts of food when they have felt an emotional state (anger, sadness, loneliness, anxiety, tiredness, boredom, guilt, happiness) and physical pain over the last 28 days. All items were rated on a 7-point scale ranging from 0 ("no days") to 6 ("everyday"). The higher the score, the higher the level of emotional overeating. To obtain a Polish translation, we used a standard forward-backward translation procedure. In our study, Cronbach's alpha coefficient was acceptable $(\alpha=0.91)$.

\subsubsection{The Eating Motivation Survey (EMS)}

To assess how often people eat for health reasons, to control body weight, and to regulate emotion, participants completed the Eating Motivation Survey [38]. The 45-item EMS includes the following 15 subscales measuring different eating motives: habits, need and hunger, liking, health, pleasure, traditional eating, convenience, natural concerns, price, visual appeal, sociability, weight control, affect regulation, social image, social norms. Due to the aim of the study, only three subscales were selected for analysis-health, weight control, affect regulation. All items were rated on a 7-point scale ranging from 1 ("never") to 7 ("always"). The higher the score, the more strongly eating is determined by health, weight control, and affect regulation. To obtain a Polish translation, we used a standard forward-backward translation procedure. In our study, Cronbach's alpha coefficient was acceptable $\left(\alpha_{\text {health }}=0.82, \alpha_{\text {weightcontrol }}=0.81, \alpha_{\text {affectregulation }}=0.80\right)$.

\subsubsection{The Mindful Eating Questionnaire (MEQ)}

To assess mindful eating, participants completed the Mindful Eating Questionnaire [42]. The 20-item EMS includes two subscales: (a) recognition-eating is conditioned by hunger and satiety, (b) awareness - eating while being aware of physiological and psychological experiences. All items were rated on a 4-point scale ranging from 1 ("never/rarely") to 4 ("usually/always"). The higher the score, the more mindfully people eat. To obtain a 
Polish translation, we used a standard forward-backward translation procedure. In our study, Cronbach's alpha coefficient was acceptable $\left(\alpha_{\text {recognition }}=0.70, \alpha_{\text {awareness }}=0.82\right)$.

\subsubsection{COVID-19-Related Stress}

To assess COVID-19-related stress, participants were asked "Is the current epidemiological situation related to COVID-19 stressful for you?" and they could choose to respond: "No" (0) or "Yes" (1) (a dummy-coded variable).

\subsubsection{Sociodemographic Variables}

Participants were asked about gender, weight, height, age, sexual orientation, and ethnicity. Body mass index (BMI; $\mathrm{kg} / \mathrm{m}^{2}$ ) was calculated based on self-reported weight and height. Based on the World Health Organization guidelines [43], women were divided into two groups: (a) healthy body weight: $18.5 \leq \mathrm{BMI} \leq 24.99 \mathrm{~kg} / \mathrm{m}^{2}$, and (b) overweight (pre-obesity and obesity): BMI $\geq 25 \mathrm{~kg} / \mathrm{m}^{2}$.

\subsection{Statistical Analysis}

A two-step cluster analysis (with Schwarz's Bayesian criterion) was chosen to identify clusters based on BMI, COVID-related stress, and body dissatisfaction. This analysis is appropriate for samples larger than 200 and for both categorical and continuous variables [44]. One-way analysis of variance (ANOVA) with Bonferroni multiple comparison tests was used to assess differences between the clusters with regard to emotional overeating, eating motives (health, weight control, affect regulation), and mindful eating (recognition, awareness). The significance level was defined as $p<0.05$. All analyses were conducted using IBM SPSS Statistic version 26 (IBM, Armonk, New York, United States).

\section{Results}

\subsection{Cluster Analysis of Weight Status (BMI), COVID-19-Related Stress, and Body Dissatisfaction}

The analysis included 1354 Polish women who ranged in: (a) body weight from 45 to $130 \mathrm{~kg}(M=67.02, S D=13.04)$, (b) height from 146 to $188 \mathrm{~cm}(M=166.22, S D=6.09)$, and (c) body mass index (BMI) from 18.50 to $47.96 \mathrm{~kg} / \mathrm{m}^{2}(M=24.23 S D=4.40)$. Nine hundred and eleven women $(67.28 \%)$ had normal body weight, and 443 women $(32.72 \%)$ were overweight.

The cluster analysis technique revealed four distinct clusters (Table 1): (a) Cluster 1 ( $N=314)$ : healthy body weight, no COVID-related stress, and low body dissatisfaction $(M=1.19)$; (b) Cluster 2 ( $N=131)$ : overweight, no COVID-related stress, and high body dissatisfaction $(M=2.41)$; (c) Cluster $3(N=597)$ : healthy body weight, COVID-related stress, and low body dissatisfaction $(M=1.27)$; $(\mathrm{d})$ Cluster $4(N=312)$ : overweight, COVIDrelated stress, and high body dissatisfaction $(M=2.84)$.

Table 1. Between-cluster differences: age, body mass index, emotional overeating, eating motives, and mindful eating.

\begin{tabular}{|c|c|c|c|c|c|}
\hline & $\begin{array}{c}\text { CLUSTER 1 } \\
\text { (N=314): } \\
\text { Healthy Body } \\
\text { Weight } \\
\text { + No } \\
\text { COVID-Related } \\
\text { Stress } \\
\text { + Low Body } \\
\text { Dissatisfaction } \\
\text { (CDRS) }\end{array}$ & $\begin{array}{c}\text { CLUSTER } 2 \\
(N=131): \\
\text { Overweight } \\
+ \text { No } \\
\text { COVID-Related } \\
\text { Stress } \\
\text { + High Body } \\
\text { Dissatisfaction } \\
\text { (CDRS) }\end{array}$ & $\begin{array}{c}\text { CLUSTER } 3 \\
(N=597): \\
\text { Healthy Body } \\
\text { Weight } \\
\text { + COVID-Related } \\
\text { Stress } \\
\text { + Low Body } \\
\text { Dissatisfaction } \\
\text { (CDRS) }\end{array}$ & $\begin{array}{c}\text { CLUSTER 4 } \\
\text { (N = 312): } \\
\text { Overweight } \\
\text { + COVID-Related } \\
\text { Stress } \\
\text { + High Body } \\
\text { Dissatisfaction } \\
\text { (CDRS) }\end{array}$ & \\
\hline & \multicolumn{4}{|c|}{$M(S D)$} & Post hoc \\
\hline \multicolumn{6}{|c|}{$F(3,1350)=45.01, p<0.001, \eta_{p}^{2}=0.09$} \\
\hline Age & $29.41(10.00)$ & 36.08 (11.27) & $29.63(10.46)$ & 36.95 (11.31) & $\begin{array}{l}1 \text { vs. } 2^{* * *} \\
1 \text { vs. } 3 \\
1 \text { vs. } 4^{* * *} \\
2 \text { vs. } 3^{* * *} \\
2 \text { vs. } 4 \\
3 \text { vs. } 4^{* * *}\end{array}$ \\
\hline
\end{tabular}


Table 1. Cont

\begin{tabular}{|c|c|c|c|c|c|}
\hline & $\begin{array}{c}\text { CLUSTER 1 } \\
(N=314): \\
\text { Healthy Body } \\
\text { Weight } \\
\text { + No } \\
\text { COVID-Related } \\
\text { Stress } \\
\text { + Low Body } \\
\text { Dissatisfaction } \\
\text { (CDRS) }\end{array}$ & $\begin{array}{c}\text { CLUSTER } 2 \\
\text { (N = 131): } \\
\text { Overweight } \\
\text { + No } \\
\text { COVID-Related } \\
\text { Stress } \\
\text { + High Body } \\
\text { Dissatisfaction } \\
\text { (CDRS) }\end{array}$ & $\begin{array}{c}\text { CLUSTER } 3 \\
\text { ( }=597): \\
\text { Healthy Body } \\
\text { Weight } \\
\text { + COVID-Related } \\
\text { Stress } \\
\text { + Low Body } \\
\text { Dissatisfaction } \\
\text { (CDRS) }\end{array}$ & $\begin{array}{c}\text { CLUSTER } 4 \\
\text { (N=312): } \\
\text { Overweight } \\
+ \text { COVID-Related } \\
\text { Stress } \\
+ \text { High Body } \\
\text { Dissatisfaction } \\
\text { (CDRS) }\end{array}$ & \\
\hline & \multicolumn{4}{|c|}{$M(S D)$} & Post hoc \\
\hline \multicolumn{6}{|c|}{$F(3,1350)=699.80, p<0.001, \eta_{p}^{2}=0.61$} \\
\hline Body mass index & $21.91(1.81)$ & $29.19(4.30)$ & $21.80(1.79)$ & 29.15 (3.98) & $\begin{array}{l}1 \text { vs. } 2^{* * *} \\
1 \text { vs. } 3^{* * *} \\
1 \text { vs. } 4^{* * *} \\
2 \text { vs. } 3^{* * *} \\
2 \text { vs. } 4^{* * *} \\
3 \text { vs. } 4^{* * *}\end{array}$ \\
\hline EOQ & & $F(3,1350)=13.08$ & $<0.001, \eta_{p}^{2}=0.03$ & & \\
\hline $\begin{array}{l}\text { Emotional } \\
\text { overeating }\end{array}$ & $4.65(6.45)$ & $4.83(6.72)$ & $6.10(7.20)$ & $8.31(10.20)$ & $\begin{array}{l}1 \text { vs. } 2^{2} \\
1 \text { vs. } 3^{*} \\
1 \text { vs. } 4^{* * *} \\
2 \text { vs. } 3^{* * *} \\
2 \text { vs. } 4^{* * *} \\
3 \text { vs. } 4^{* * *}\end{array}$ \\
\hline EMS & & \multicolumn{3}{|c|}{$F(3,1350)=9.25, p<0.001, \eta_{p}^{2}=0.02$} & \\
\hline Health & $12.76(4.39)$ & $11.90(4.72)$ & $13.13(4.52)$ & $11.60(4.29)$ & $\begin{array}{c}1 \text { vs. } 2 \\
1 \text { vs. } 3 \\
1 \text { vs. } 4^{* *} \\
2 \text { vs. } 3^{*} \\
2 \text { vs. } 4^{*} \\
3 \text { vs. } 4^{* * *}\end{array}$ \\
\hline EMS & & \multicolumn{3}{|c|}{$F(3,1350)=1.83, p>0.05, \eta_{p}^{2}=0.004$} & \\
\hline Weight control & $10.32(4.24)$ & $10.51(4.42)$ & $10.99(4.51)$ & $10.58(4.10)$ & $\begin{array}{l}1 \text { vs. } 2 \\
1 \text { vs. } 3 \\
1 \text { vs. } 4 \\
2 \text { vs. } 3 \\
2 \text { vs. } 4 \\
3 \text { vs. } 4 \\
\end{array}$ \\
\hline EMS & & \multicolumn{3}{|c|}{$F(3,1350)=13.31, p<0.001, \eta_{p}^{2}=0.03$} & \\
\hline Affect regulation & $6.88(3.64)$ & $7.67(4.45)$ & $7.94(4.15)$ & $9.02(4.94)$ & $\begin{array}{c}1 \text { vs. } 2^{2} \\
1 \text { vs. } 3^{* *} \\
1 \text { vs. } 4^{* * *} \\
2 \text { vs. } 3^{*} \\
2 \text { vs. } 4^{*} \\
3 \text { vs. } 4^{* *}\end{array}$ \\
\hline MEQ & & \multicolumn{3}{|c|}{$F(3,1350)=8.01, p<0.001, \eta_{p}{ }^{2}=0.02$} & \\
\hline Recognition & $26.95(4.31)$ & $25.92(4.42)$ & $26.43(4.66)$ & $25.26(4.54)$ & $\begin{array}{c}1 \text { vs. } 2 \\
1 \text { vs. } 3 \\
1 \text { vs. } 4^{* * *} \\
2 \text { vs. } 3 \\
2 \text { vs. } 4 \\
3 \text { vs. } 4^{* *}\end{array}$ \\
\hline MEQ & & \multicolumn{3}{|c|}{$F(3,1350)=4.52, p<0.01, \eta_{p}^{2}=0.01$} & \\
\hline Awareness & $30.92(6.93)$ & $29.33(7.20)$ & $31.46(6.68)$ & $30.27(6.80)$ & $\begin{array}{c}1 \text { vs. } 2 \\
1 \text { vs. } 3 \\
1 \text { vs. } 4 \\
2 \text { vs. } 3^{* *} \\
2 \text { vs. } 4 \\
3 \text { vs. } 4^{4}\end{array}$ \\
\hline
\end{tabular}

EOQ— the Emotional Overeating Questionnaire; EMS—-the Eating Motivation Survey; MEQ— the Mindful Eating Questionnaire; healthy body weight: $18.5 \geq \mathrm{BMI} \leq 24.99 \mathrm{~kg} / \mathrm{m}^{2}$; overweight: BMI $\geq 25 \mathrm{~kg} / \mathrm{m}^{2}$; COVID-related stress: "Yes" or "No"; CDRS-the Contour

Drawing Rating Scale; ${ }^{*} p<0.05 ;{ }^{* *} p<0.01 ; * * * 0.001 ;{ }^{*} p=0.076$. 


\subsection{Comparison of the Four Clusters for Emotional Overeating, Eating Motives, and Mindful Eating}

One-way analysis of variance (ANOVA) showed the significant effect of clusters on emotional overeating, two eating motives (health, affect regulation), and mindful eating (recognition, awareness). Table 1 shows the results of multiple comparisons.

Referring to the most important findings, our results indicated that Cluster 4 (overweight, COVID-related stress, high body dissatisfaction) had significantly greater disordered eating than Clusters 1 (healthy body weight, no COVID-related stress, low body dissatisfaction) and 3 (healthy body weight, COVID-related stress, low body dissatisfaction) and these significant differences were found with regard to emotional overeating, health motive, and affecting regulation motive of eating, and to one aspect of mindful eating - recognition. In turn, for the second aspect of mindful eating-awareness- the differences between Cluster 4 and Cluster 3 were at $p=0.076$.

Cluster 4 differed significantly from Cluster 2 (overweight, no COVID-related stress, high body dissatisfaction) in terms of emotional overeating and affect regulation motive for eating. Moreover, Cluster 1 also had a lower level of emotional overeating and affect regulation motive of eating than Cluster 3, and Cluster 3 had significantly higher health motive for eating and awareness than Cluster 2. Interestingly, in relation to weight control motive for eating, we did not find any significant differences between Clusters 1, 2, 3, and 4 , and Clusters 1 and 2 did not differ in terms of any of the analyzed variables.

Generally, our outcomes partially support our hypothesis, as higher levels of some types of disordered eating were observed in women who were overweight, with COVIDrelated stress and high body dissatisfaction as compared with women with healthy body weight, no COVID-related stress, and with low levels of body dissatisfaction. Our results indicate that body weight status, as well as COVID-19-related stress and body dissatisfaction, may contribute to the intensity of disordered eating.

\section{Discussion}

Our study examined patterns of weight status, COVID-19-related stress, and body dissatisfaction in a sample of Polish women during the COVID-19 pandemic. Four clusters were discovered. By analyzing the most important findings, significant differences (in terms of most of the assessed behaviors and eating motives) were found between women who were overweight who were simultaneously stressed by COVID-19 and had a high level of body dissatisfaction (Cluster 4), and women with a healthy body weight, who experienced no stress from COVID-19 and had a low level of body dissatisfaction (Cluster 1). Women from Cluster 4 (compared to Cluster 1) significantly more often declared that their motive for undertaking eating behavior during COVID-19 was the regulation of emotions (a subscale of the Eating Motivation Survey [38]). This tendency is also reflected in the outcomes of emotional overeating (as measured by the Emotional Overeating Questionnaire [41])—women from Cluster 4 overeat more often under the influence of various emotional states and physical pain compared to Cluster 1 . Moreover, the motive for undertaking the eating behaviour of Cluster 4 was significantly less often health, and less often that they finished their meals in response to the feeling of satiety (i.e., they more often continued their meal as a form of overeating despite the fact that they were already full; mindful eating - "recognition"). The above-described pattern of disordered eating of Cluster 4 may be particularly risky, as its consolidation may result in further weight gain and/or difficulties in effective weight reduction [34,45]. Therefore, taking into account not only emotional factors (such as stress) but also weight status and body dissatisfaction will help to better understand the mechanisms by which abnormal eating behaviour develops [36,46]. These outcomes suggest it may be of critical importance during COVID-19 to promote a healthy body image and improve emotional regulation for women who are overweight.

The importance of COVID-19-related stress for more disordered eating in a sample of Polish women may also be indicated by some of our other results. This is evidenced by significantly higher results in affect regulation motive of eating and emotional overeating 
in Cluster 4 compared to Cluster 2 (overweight, no COVID-related stress, high body dissatisfaction), and similar differences between Clusters 1 (healthy body weight, no COVID-related stress, low body dissatisfaction) and 3 (healthy body weight, COVIDrelated stress, low body dissatisfaction). Thus, both when comparing clusters composed of overweight women and women with a healthy body weight, emotional (over)eating is stronger in groups that are stressed by COVID-19. This may mean that although this tendency among women with a healthy body weight is not as strong as among those who are overweight [34,45], it is also present in the former group and may be intensified as a result of experiencing tension from COVID-19 and related restrictions. Both groups should therefore be subjected to influences/activities that will help the woman regulate her emotions in a more adaptive way than through emotional (over)eating $[15,16,25,28,31]$.

When planning some interventions, there are other important aspects to considerbody image and body weight. In the context of our research, it turns out that if women did not accept their silhouettes (and the related body weight), then their eating behaviors were more disordered. This is evidenced by the differences described above between Cluster 4 and Cluster 1, as well as the differences between Clusters 4 and 3 and between Clusters 2 and 3 . The differences between Clusters 3 and 4 show that women who are overweight, with COVID-19-related stress and high body dissatisfaction (compared to Cluster 3: healthy body weight, COVID-related stress, low body dissatisfaction) were more likely to eat under the influence of emotions and physical pain, less often likely to eat taking into account health and less often likely to eat mindfully (mindful eating subscales: "recognition" $p<0.01$ and "awareness" $p=0.076$ ). This could mean that even though both groups (Clusters 3 and 4 ) are stressed by COVID-19, more disordered eating patterns have emerged in women who are overweight and have high levels of body dissatisfaction. Furthermore, even when we compared Clusters 2 and 3 (differing in their experience of COVID-19-related stress), it turned out that in the group with high body dissatisfaction, who were overweight and had no COVID-related stress (Cluster 2), we observed a more disturbed eating (lower health motive of eating and lower awareness) compared to the group with low body dissatisfaction, healthy body weight, and COVIDrelated stress (Cluster 3).

Interestingly, it was not possible to obtain any significant differences with regard to the subscale of the Eating Motivation Survey [38] — weight control. This means that women from all clusters (with a similar frequency) were motivated to manage their own body weight through making certain food choices during the COVID-19 period. A possible explanation of these results may be related to the fact that when the possibilities of practicing physical activity in the previous way (e.g., in the gym) were limited, diet management became one of the main methods of weight control in the groups of various weight status. However, more research is needed in this regard.

Overall, our results partially support our hypothesis, as higher levels of some types of disordered eating were observed in overweight women with COVID-related stress and high body dissatisfaction, compared with women with healthy body weight, no COVID-related stress, and with low levels of body dissatisfaction. These outcomes indicate that body weight status, as well as COVID-19-related stress and body dissatisfaction, may contribute to the intensity of disordered eating. Therefore, it is important to design interventions that target changes in emotional functioning, cognitive functioning, and body image in a sample of women. These activities should include, but are not limited to, (a) managing stress, emotions, and physical pain in a more adaptive way than by (over)eating; (b) learning to accept the body, taking into account negative emotional states such as stress and anxiety, which could be aggravated by COVID-19 and its limitations; (c) learning more adaptive forms of managing one's own body weight than through disordered eating; (d) developing and consolidating a diet model in which one of the primary eating motives is health.

Our findings are important because understanding how COVID-19 experiences and people's individual predisposition (associated with body shape and weight) differentially relate to eating behaviors has direct implications for tailoring prevention efforts and 
treatment. Our study shows that COVID-19-related lockdowns and related consequences (e.g., increasing stress and concerns about body shape and weight) may affect eating behaviors. During future epidemic-related quarantines, this may be an argument in favor of organizing support regarding emotional functioning, body image, and eating behaviors, particularly for the most vulnerable groups-including overweight and obese women. Taking such actions seems to be important in the light of reports which show that disordered eating can intensify over time and lead to the development of a full syndrome of eating disorders [47]. And, as recent research shows, the problem of eating disorders has increased significantly during the COVID-19 pandemic, which was also associated with a higher percentage of patients in this group having suicidal ideation and attempting suicide [48].

Our study also had some limitations: (a) study design: a cross-sectional study; (b) participants: only female volunteers; (c) measures: only self-reported data, one-item COVIDrelated stress measurement, Cronbach's alpha for "recognition" $=0.70$, and, with regard to some measures, there is no validation on the Polish sample. It is therefore necessary to plan further studies that take into account these limitations (e.g., longitudinal studies, women and men, and comparison of their functioning, objective measurement of body weight and height, and validated instruments for measuring of stress [49] and other variables). Moreover, note that it is also possible that if the clusters have weight differences, it is likely that they already had differences in eating habits, and perhaps differences in the levels of disordered eating, independently of other variables. Therefore, one should be careful in drawing conclusions, and this issue should be taken into account in future longitudinal studies. On a final note, it is necessary to emphasize that our results may have a limited possibility of generalization due to the specificity of the lockdown conditions in Poland.

Author Contributions: Conceptualization, A.M., K.C.-B. and J.M.; methodology, A.M., K.C.-B. and J.M.; formal analysis, A.M., K.C.-B. and J.M.; investigation, A.M., K.C.-B. and J.M.; data curation, A.M., K.C.-B. and J.M.; writing-original draft preparation, A.M., K.C.-B., J.M. and P.M.; supervision, P.M.; project administration, A.M., K.C.-B. and J.M.; funding acquisition, K.C.-B. All authors have read and agreed to the published version of the manuscript.

Funding: The publication is financed by the University of Wrocław.

Institutional Review Board Statement: The study was conducted according to the guidelines of the Declaration of Helsinki and approved by the Ethics Committee form University of the Bielsko-Biała (no. 2021/2/2E/2).

Informed Consent Statement: Informed consent was obtained from all subjects involved in the study.

Data Availability Statement: The data that support the findings of this study are available from the corresponding author upon reasonable request.

Conflicts of Interest: The authors declare no conflict of interest.

\section{References}

1. Johns Hopkins University. COVID-19 Dashboard by the Center for Systems Science and Engineering (CSSE) at Johns Hopkins University (JHU). Johns Hopkins University \& Medicine Coronavirus Resource Center. Available online: https:/ / coronavirus.jhu. edu/map.html (accessed on 1 October 2021).

2. Kumar, A.; Nayar, K.R. COVID-19 and its mental health consequences. J. Ment. Health. 2021, 30, 1-2. [CrossRef]

3. World Health Organization. Mental Health and Psychosocial Considerations during the COVID-19 Outbreak. Available online: https:/ / www.who.int/docs/default-source/coronaviruse/mental-health-considerations.pdf (accessed on 1 October 2021).

4. Gallagher, M.W.; Zvolensky, M.J.; Long, L.J.; Rogers, A.H.; Garey, L. The Impact of COVID-19 Experiences and Associated Stress on Anxiety, Depression, and Functional Impairment in American Adults. Cognit. Ther. Res. 2020, 44, 1043-1051. [CrossRef] [PubMed]

5. Rahman, M.A.; Hoque, N.; Alif, S.M. Factors associated with psychological distress, fear and coping strategies during the COVID-19 pandemic in Australia. Glob. Health 2020, 16, 95. [CrossRef]

6. Cielo, F.; Ulberg, R.; Di Giacomo, D. Psychological Impact of the COVID-19 Outbreak on Mental Health Outcomes among Youth: A Rapid Narrative Review. Int. J. Environ. Res. 2021, 18, 6067. [CrossRef] [PubMed] 
7. Gruber, J.; Prinstein, M.J.; Clark, L.A.; Rottenberg, J.; Abramowitz, J.S.; Albano, A.M.; Aldao, A.; Borelli, J.L.; Chung, T.; Davila, J.; et al. Mental health and clinical psychological science in the time of COVID-19: Challenges, opportunities, and a call to action. Am. Psychol. 2021, 76, 409-426. [CrossRef] [PubMed]

8. Park, K.H.; Kim, A.R.; Yang, M.A.; Lim, S.J.; Park, J.H. Impact of the COVID-19 pandemic on the lifestyle, mental health, and quality of life of adults in South Korea. PLOS ONE 2021, 16, e0247970. [CrossRef] [PubMed]

9. Pfefferbaum, B.; North, C.S. Mental Health and the COVID-19 Pandemic. N. Engl. J. Med. 2020, 383, 510-512. [CrossRef]

10. Yao, H.; Chen, J.H.; Xu, Y.F. Patients with mental health disorders in the COVID-19 epidemic. Lancet Psychiatry 2020,7 , e21. [CrossRef]

11. Wang, C.; Pan, R.; Wan, X.; Tan, Y.; Xu, L.; Ho, C.S.; Ho, R.C. Immediate Psychological Responses and Associated Factors during the Initial Stage of the 2019 Coronavirus Disease (COVID-19) Epidemic among the General Population in China. Int. J. Environ. Res. 2020, 17, 1729. [CrossRef]

12. Ammar, A.; Brach, M.; Trabelsi, K.; Chtourou, H.; Boukhris, O.; Masmoudi, L.; Bouaziz, B.; Bentlage, E.; How, D.; Ahmed, M.; et al. Effects of COVID-19 Home Confinement on Eating Behaviour and Physical Activity: Results of the ECLB-COVID19 International Online Survey. Nutrients 2020, 12, 1583. [CrossRef] [PubMed]

13. Robinson, E.; Boyland, E.; Chisholm, A.; Harrold, J.; Maloney, N.G.; Marty, L.; Mead, B.R.; Noonan, R.; Hardman, C.A. Obesity, eating behavior and physical activity during COVID-19 lockdown: A study of UK adults. Appetite 2021, 156, 104853. [CrossRef] [PubMed]

14. Sidor, A.; Rzymski, P. Dietary Choices and Habits during COVID-19 Lockdown: Experience from Poland. Nutrients 2020, $12,1657$. [CrossRef]

15. Al-Musharaf, S. Prevalence and Predictors of Emotional Eating among Healthy Young Saudi Women during the COVID-19 Pandemic. Nutrients 2020, 12, 2923. [CrossRef]

16. Cecchetto, C.; Aiello, M.; Gentili, C.; Ionta, S.; Osimo, S.A. Increased emotional eating during COVID-19 associated with lockdown, psychological and social distress. Appetite 2021, 160, 105122. [CrossRef]

17. Modrzejewska, A.; Czepczor-Bernat, K.; Modrzejewska, J.; Matusik, P. Eating Motives and Other Factors Predicting Emotional Overeating during COVID-19 in a Sample of Polish Adults. Nutrients 2021, 13, 1658. [CrossRef]

18. Cooper, M.; Reilly, E.; Siegel, J.; Coniglio, K.; Sadeh-Sharvit, S.; Pisetsky, E.; Anderson, L. Eating disorders during the COVID-19 pandemic and quarantine: An overview of risks and recommendations for treatment and early intervention. Eat. Disord. 2020, 1-23. [CrossRef] [PubMed]

19. Czepczor-Bernat, K.; Swami, V.; Modrzejewska, A.; Modrzejewska, J. COVID-19-Related Stress and Anxiety, Body Mass Index, Eating Disorder Symptomatology, and Body Image in Women from Poland: A Cluster Analysis Approach. Nutrients 2021, 13, 1384. [CrossRef] [PubMed]

20. Touyz, S.; Lacey, H.; Hay, P. Eating disorders in the time of COVID-19. J. Eat. Disord. 2020, 8, 19. [CrossRef] [PubMed]

21. Rodgers, R.F.; Lombardo, C.; Cerolini, S.; Franko, D.L.; Omori, M.; Fuller-Tyszkiewicz, M.; Linardon, J.; Courtet, P.; Guillaume, S. The impact of the COVID-19 pandemic on eating disorder risk factors and symptoms. Int. J. Eat. Disord. 2020, 53, 1166-1170. [CrossRef]

22. Swami, V.; Horne, G.; Furnham, A. COVID-19-related stress and anxiety are associated with negative body image in adults from the United Kingdom. Personal. Individ. Differ. 2021, 170, 110426. [CrossRef] [PubMed]

23. Sahin, S.; Sezer, H.; Cicek, E.; Yagız Ozogul, Y.; Yildirim, M.; Icli, T.B.; Polat Korkmaz, O.; Durcan, E.; Sulu, C.; Somay, K.; et al. The Role of Obesity in Predicting the Clinical Outcomes of COVID-19. Obes. Facts 2021, 92, 481-489. [CrossRef] [PubMed]

24. Barcın-Güzeldere, H.; Devrim-Lanpir, A. The Association Between Body Mass Index, Emotional Eating and Perceived Stress during COVID-19 Partial Quarantine in Healthy Adults. Public Health Nutr. 2021, 1-8. [CrossRef] [PubMed]

25. Mason, T.B.; Barrington-Trimis, J.; Leventhal, A.M. Eating to Cope With the COVID-19 Pandemic and Body Weight Change in Young Adults. J. Adolesc. Health 2021, 68, 277-283. [CrossRef]

26. Yau, Y.H.; Potenza, M.N. Stress and eating behaviors. Minerva Endocrinol. 2013, 38, 255-267. [PubMed]

27. Armitage, R.; Nellums, L.B. COVID-19 and the consequences of isolating the elderly. Lancet Public Health 2020, 5, e256. [CrossRef]

28. Coulthard, H.; Sharps, M.; Cunliffe, L.; van den Tol, A. Eating in the lockdown during the Covid 19 pandemic; self-reported changes in eating behaviour, and associations with BMI, eating style, coping and health anxiety. Appetite 2021, 161, 105082. [CrossRef] [PubMed]

29. Institute of Medicine. Weight Management: State of the Science and Opportunities for Military Programs; The National Academies Press: Washington, DC, USA, 2013. [CrossRef]

30. Weissman, R.S.; Bauer, S.; Thomas, J.J. Access to evidence-based care for eating disorders during the COVID-19 crisis. Int. J. Eat. Disord. 2020, 53, 369-376. [CrossRef]

31. Zhou, Y.; Wade, T.D. The impact of COVID-19 on body-dissatisfied female university students. Int. J. Eat. Disord. 2021, 54, 1283-1288. [CrossRef] [PubMed]

32. Przybyłowicz, K.E.; Jesiołowska, D.; Obara-Gołębiowska, M.; Antoniak, L. A subjective dissatisfaction with body weight in young women: Do eating behaviours play a role? Rocz. Panstw. Zakl. Hig. 2014, 65, 243-249.

33. Weinberger, N.A.; Kersting, A.; Riedel-Heller, S.G.; Luck-Sikorski, C. Body Dissatisfaction in Individuals with Obesity Compared to Normal-Weight Individuals: A Systematic Review and Meta-Analysis. Obes. Facts 2016, 9, 424-441. [CrossRef] [PubMed]

34. Frayn, M.; Knäuper, B. Emotional eating and weight in adults: A review. Curr. Psychol. 2018, 37, 924-933. [CrossRef] 
35. McAtamney, K.; Mantzios, M.; Egan, H.; Wallis, D.J. Emotional eating during COVID-19 in the United Kingdom: Exploring the roles of alexithymia and emotion dysregulation. Appetite 2021, 161, 105120. [CrossRef] [PubMed]

36. Rossy, L. The Mindfulness-Based Eating Solution: Proven Strategies to End Overeating, Satisfy Your Hunger, and Savor Your Life; New Harbinger Publications: Oakland, CA, USA, 2016.

37. Pintado-Cucarella, S.; Rodríguez-Salgado, P. Mindful eating and its relationship with body mass index, binge eating, anxiety and negative affect. J. Health. Soc. Behav. 2016, 8, 19-24. [CrossRef]

38. Renner, B.; Sproesser, G.; Strohbach, S.; Schupp, H.T. Why we eat what we eat. The Eating Motivation Survey (TEMS). Appetite 2012, 59, 117-128. [CrossRef]

39. Robertson, M.; Duffy, F.; Newman, E.; Prieto Bravo, C.; Ates, H.; Sharpe, H. Exploring changes in body image, eating and exercise during the COVID-19 lockdown: A UK survey. Appetite 2021, 159, 105062. [CrossRef] [PubMed]

40. Thompson, M.A.; Gray, J.J. Development and validation of a new body image assessment scale. J. Personal. Assess. 1995, 64, 258-269. [CrossRef] [PubMed]

41. Masheb, R.M.; Grilo, C.M. Emotional overeating and its associations with eating disorder psychopathology among overweight patients with binge eating disorder. Int. J. Eat. Disord. 2006, 39, 141-146. [CrossRef]

42. Clementi, C.; Casu, G.; Gremigni, P. An Abbreviated Version of the Mindful Eating Questionnaire. J. Nutr. Educ. Behav. 2017, 49, 352-356.e1. [CrossRef]

43. World Health Organization. Body Mass Index-BMI. Available online: https://www.euro.who.int/en/health-topics/diseaseprevention/nutrition/a-healthy-lifestyle/body-mass-index-bmi (accessed on 1 October 2021).

44. Bittmann, R.M.; Gelbard, R.M. Decision-making method using a visual approach for cluster analysis problems; indicative classification algorithms and grouping scope. Expert. Syst. 2007, 24, 171-187. [CrossRef]

45. Frayn, M.; Livshits, S.; Knäuper, B. Emotional eating and weight regulation: A qualitative study of compensatory behaviors and concerns. J. Eat. Disord. 2018, 6, 23. [CrossRef]

46. He, Z.H.; Li, M.D.; Liu, C.J.; Ma, X.Y. Relationship between body image, anxiety, food-specific inhibitory control, and emotional eating in young women with abdominal obesity: A comparative cross-sectional study. Arch. Public Health 2021, 79, 11. [CrossRef] [PubMed]

47. Shisslak, C.M.; Crago, M.; Estes, L.S. The spectrum of eating disturbances. Int. J. Eat. Disord. 1995, 18, 209-219. [CrossRef]

48. Taquet, M.; Geddes, J.; Luciano, S.; Harrison, P. Incidence and outcomes of eating disorders during the COVID-19 pandemic. Br. J. Psychiatry 2021, 1-3. [CrossRef]

49. Campo-Arias, A.; Pedrozo-Cortés, M.J.; Pedrozo-Pupo, J.C. Pandemic-Related Perceived Stress Scale of COVID-19: An exploration of online psychometric performance. Rev. Colomb. Psiquiatr. 2020, 49, 229-230. [CrossRef] [PubMed] 